\title{
Letter to the editor: Australian immunisation registers: established foundations and opportunities for improvement
}

S L Sheridan (s.sheridan@uq.edu.au) $)^{1,2}$, S B Lambert ${ }^{1,3}$

1. Queensland Children's Medical Research Institute, Royal Children's Hospital, The University of Queensland, Brisbane, Australia

2. School of Population Health, The University of Queensland, Brisbane, Australia

3. Communicable Diseases Branch, Queensland Health, Brisbane, Australia

Citation style for this article:

Sheridan SL, Lambert SB. Letter to the editor: Australian immunisation registers: established foundations and opportunities for improvement . Euro Surveill. 2012;17(21): pii=20177. Available online: http://www.eurosurveillance.org/ViewArticle.aspx?Articleld=20177

Article submitted on 21 May 2012 / published on 24 May 2012

\section{To the editor:}

In their recent article on the Australian immunisation registers [1] Chin et al. recognise the potential value of linking immunisation registers with healthcare outcome data for public health benefit by enabling rapid investigation of population-level vaccine safety and effectiveness. While the national Australian Childhood Immunisation Register (ACIR) has been linked on two occasions to examine vaccine safety, $[2,3]$ it has not been linked to health outcome data to investigate vaccine effectiveness.

As Chin et al. mention, Queensland and the Northern Territory have separate jurisdiction-level immunisation registers. These registers, which are not subject to the same privacy legislation inhibiting linkage of ACIR data, have been used to calculate effectiveness for rotavirus [4,5], pneumococcal [6] and pertussis-containing vaccines (unpublished data) by linking immunisation with outcome data such as hospitalisations and disease notifications.

These studies demonstrate the usefulness of linking data from immunisation registers to assess vaccine effectiveness and the importance jurisdiction-level immunisation registers have played in allowing evaluation of large publicly-funded immunisation programmes.

Individual privacy must be protected. However, data linkage does not pose a significant threat to privacy and has the potential to contribute efficiently and substantially to public health. One could argue that the ethical obligation, seen from a population as well as individual perspective, is to ensure routinely-collected health information is efficiently and optimally used to achieve the greatest public benefit, while protecting the individual's privacy.
In setting up jurisdictional or national immunisation registers to achieve the greatest public benefit, we recommend thought be given to enabling easy linkage of data, in practical and legal terms, between immunisation and health outcome data.

\section{References}

1. Chin LK, Crawford NW, Rowles G, Buttery JP. Australian immunisation registers: established foundations and opportunities for improvement . Euro Surveill. 2012;17(16): pii=20148. Available from: http://www. eurosurveillance.org/ViewArticle.aspx?Articleld $=20148$

2. Buttery JP, Danchin MH, Lee KJ, Carlin JB, Mclntyre PB, Elliott EJ, et al. Intussusception following rotavirus vaccine administration: post-marketing surveillance in the National Immunization Program in Australia. Vaccine. 2011;29(16):3061-6.

3. Gold M, Dugdale S, Woodman RJ, McCaul KA. Use of the Australian Childhood Immunisation Register for vaccine safety data linkage. Vaccine. 2010;28(26):4308-11.

4. Snelling TL, Andrews RM, Kirkwood CD, Culvenor S, Carapetis JR. Case-control evaluation of the effectiveness of the G1P[8] human rotavirus $\mathrm{G}_{2} \mathrm{P}[4]$ infection in Central Australia. Clin Infect Dis. 2011;52(2):191-9.

5. Field EJ, Vally H, Grimwood K, Lambert SB. Pentavalent rotavirus vaccine and prevention of gastroenteritis hospitalizations in Australia. Pediatrics. 2010;126(3);e506-12.

6. O'Grady KF, Lee KJ, Carlin JB, Torzillo PJ, Chang AB, Mulholland EK, et al. Increased risk of hospitalization for acute lower respiratory tract infection among Australian Indigenous infants $5-23$ months of age following pneumococcal vaccination: a cohort study. Clin Infect Dis. 2010;50(7):970-8 